\title{
Boiling heat transfer on single phosphor bronze and copper mesh microstructures
}

\author{
Łukasz J. Orman $^{1 \mathrm{a}}$ \\ ${ }^{1}$ Kielce University of Technology, 25-314 Kielce, Poland
}

\begin{abstract}
The paper presents experimental results of boiling heat transfer of distilled water and ethyl alcohol on surfaces covered with single layers of wire mesh structures made of phosphor bronze and copper. For each material two kinds of structures have been considered (higher and lower) in order to determine the impact of the height of the structure on boiling heat transfer. The wire diameter of the copper meshes was $0,25 \mathrm{~mm}$ and $0,32 \mathrm{~mm}$, while of the bronze meshes: $0,20 \mathrm{~mm}$ and $0,25 \mathrm{~mm}$. The structures had the same mesh aperture (distance between the wires $-0,50 \mathrm{~mm}$ for copper and 0,40 for bronze) but different wire diameter and, consequently, different height of the layers. The tests have been performed under ambient pressure in the pool boiling mode. The obtained results indicate a visible impact of the layer height on the boiling heat transfer performance of the analysed microstructures.
\end{abstract}

\section{Introduction}

Boiling heat transfer is highly efficient in dissipating large heat fluxes at small temperature differences. In order to further intensify the heat exchange process some additional coatings might be applied on smooth heaters. These coatings enable to dissipate much higher heat fluxes than those of smooth surfaces - one of the most useful and practical covering is the metal mesh microstructure. Besides, the boiling process is initiated at lower temperature differences, which is an additional advantage.

The mesh layers have been investigated in former research projects both by the author and other researchers. Hasegawa et al. [1] experimentally analysed boiling of water at ambient pressure on a copper heater with one and two stainless steel mesh layers and a bronze layer. The wire diameter of the considered meshes ranged from 0,065 to $0,295 \mathrm{~mm}$ and their aperture from 0,104 to $0,552 \mathrm{~mm}$. At low heat fluxes no considerable influence of the coating was observed, except for the finest mesh, which produced much bigger heat flux than the other samples. Nevertheless, this heat transfer augmentation diminished as superheat rose. Smirnov and Afanasiev [2] focused their experiments on boiling heat transfer of water, ethanol and R-113 under pressures from 0,005 to $0,1 \mathrm{MPa}$. The tests were conducted on heat pipes with the inside coating of copper, bronze and stainless steel meshes of $40-450 \mu \mathrm{m}$ aperture. The number of meshes of each covering was from 1 to 24 . It was shown that such coatings improved heat transfer at low superheats. Besides authors claimed that the heat transfer coefficient is not generally dependent on the heat flux for mesh layers of aperture smaller than $0,04-0,07 \mathrm{~mm}$ and that the increase in aperture led to lower values of the heat transfer coefficient. Tolubinskij et al. [3] tested boiling of water at pressures from $0,02-0,5 \mathrm{MPa}$ on a surface covered with a single mesh made of stainless steel of apertures $0,04-3 \mathrm{~mm}$. The authors claimed that the value of mesh aperture in relation to the diameter of departing bubbles influences heat transfer on single layers of mesh. In the case of apertures smaller than the diameter of bubbles, the bubbles grow outside the mesh structure. If the aperture has a similar value as the diameter, the bubbles grow within the inside tunnels. For the apertures larger than the diameter bubbles grows on the heater surface. Vasil'yev [4] experimentally analysed boiling heat transfer of water under pressures in the range of $1-100 \mathrm{kPa}$ on a surface with a stainless steel mesh. The wire diameter was $0,055 \mathrm{~mm}, 0,09 \mathrm{~mm}, 0,15 \mathrm{~mm}$ and $0,26 \mathrm{~mm}$ and aperture $0,08 \mathrm{~mm}, 0,14 \mathrm{~mm}, 0,40 \mathrm{~mm}$ and $0,73 \mathrm{~mm}$, respectively. It was noticed that the heat transfer coefficient rose with smaller apertures. In this case of the most efficient mesh $(0,055 \mathrm{~mm}$ of wire diameter and aperture of $0,08 \mathrm{~mm}$ ) the heat transfer coefficient was $30-40 \%$ higher than for the smooth surface. Tsay et al. [5] considered water boiling on a smooth and rough surfaces covered with a stainless steel mesh coating. The investigated aperture and wire diameter were: $1,2875 \mathrm{~mm} / 0,3 \mathrm{~mm}, 0,5083 \mathrm{~mm} / 0,55 \mathrm{~mm}$ and $0,338 \mathrm{~mm} / 0,17 \mathrm{~mm}$. It was observed that the use of a single mesh led to enhanced heat transfer in relation to the smooth surface at superheats above $6{ }^{\circ} \mathrm{C}$. The visualisation analyses showed that the number of bubbles

\footnotetext{
$\bar{a}$ Corresponding author: orman@tu.kielce.pl
} 
created on the surface with the mesh was higher in comparison to the smooth surface. Liu et al. [6] carried out experiments of methanol and HFE-7100 boiling on the surface with a stainless steel mesh coating. The wire diameter was varied from $0,338 \mathrm{~mm}$ to $0,63 \mathrm{~mm}$ while aperture from $0,17 \mathrm{~mm}$ to $1,91 \mathrm{~mm}$. The values of heat flux for all the analysed microstructural samples was higher than of the smooth surface at superheats of a few Kelvin. Brausch and Kew [7] reported that a single mesh layer improved boiling heat transfer in comparison to the smooth surface at superheats up to $15 \mathrm{~K}$, which was explained by the creation of additional nucleation sites. At low values of superheat the enhancement was most significant for finer meshes. Gerlach and Joshi [8] considered PF 5060 dielectric liquid as the boiling liquid. A horizontal $9 \mathrm{~mm} \times 9 \mathrm{~mm}$ surface coated with single copper and bronze meshes soldered to a copper block was analysed. The tests were conducted for the cases when the mesh was open in a liquid pool and when it was covered with a plate. The application of the coating as it was open to the pool generally led to an increase in heat flux in comparison with the smooth surface. Franco et al. [9] investigated boiling of dielectric refrigerant R141b on wire mesh structures of wire diameter from 0,1 to $1 \mathrm{~mm}$ and aperture from 0,1 to $2,5 \mathrm{~mm}$. The critical heat flux for the meshed surface was found to be even $40 \%$ higher than for the smooth surface. It was also observed that the mesh layer enhanced heat transfer especially at low superheats. Li and Peterson [10] focused on water boiling on copper meshes and found out that the application of such structures enhanced boiling heat transfer in relation to the smooth surface. The authors analysed wire meshes of the following diamentions: wire diameter $\mathrm{d}=56 \mu \mathrm{m}$ and aperture $\mathrm{a}=119,3 \mu \mathrm{m}, \mathrm{d}=114 \mu \mathrm{m}$ and $\mathrm{a}=139,7 \mu \mathrm{m}$ as well as $\mathrm{d}=191 \mu \mathrm{m}$ and $\mathrm{a}=232,8 \mu \mathrm{m}$. Wong and Kao [11] considered heat pipes performance with a two layered mesh wick coating under water evaporation/boiling conditions. It was reported that in the case of the coarse mesh nucleate boiling was absent at low heat loads, while the dissipation of heat was attributed to surface evaporation on the water-vapour menisci within the wires. Rising heat load led to the water - vapour interface recedding into more curved menisci to provide a bigger area for evaporation and capillary force for liquid supply. It was also stated that the fine mesh provided more nucleation sites. Similarly, Liou et al. [12] also analysed heat pipes with multi-layer copper meshes sintered to their surface with water as the working liquid. Coatings of the height from $0,26 \mathrm{~mm}$ to $0,8 \mathrm{~mm}$ were formed for the presented investigations. The authors of the paper have concluded that as heat load rose, water film receded to form corrugated menisci in the microstructure and evaporation resistance decreased until partial dryout took place. Recently, Orzechowski and Tyburczyk [13] investigated water boiling on a single mesh layer made of copper of $0,2 \mathrm{~mm}$ wire diameter and 0,32 wire dimension. The mesh was coated on a fin and its effectiveness was determined as a function of superheat.

\section{Material and method}

The presented tests have been performed with distilled water and ethyl alcohol as working fluids on the surfaces covered with single layers of phosphor bronze and copper mesh layers. The bronze samples had the aperture (distance between the wires) of $0,40 \mathrm{~mm}$ and different wire diameters: $0,20 \mathrm{~mm}$ and $0,25 \mathrm{~mm}$. The aperture of the copper meshes was $0,50 \mathrm{~mm}$, while their wire diameters: $0,25 \mathrm{~mm}$ and $0,32 \mathrm{~mm}$. The meshes were sintered to the copper discs in the reduction atmosphere of hydrogen to prevent oxidation. Consequently, strong bonds were created between the disc and the microstructure.

The tests have been conducted on the experimental stand whose main element has been presented in Figure 1. The samples (copper discs with microstructures) were soldered to the copper block, in which the electric heater was located. The power of the heater was increased during the measurements with autotransformer with steps in order to provide several measurement points. During the tests heat flux transferred to the samples was calculated and the temperature under the sample was recorded. Consequently, it was possible to draw boiling curves which provide information on the boiling performance of each investigated sample. The boiling curve is a dependence of heat flux dissipated from the surface as a function of superheat (a difference between the heater temperature and the saturation temperature). Boiling took place in the thermally - resistant glass vessel located above the horizontal sample. The produced vapour is condensed in the condenser, to which cold water is provided. The condensate is returned to the vessel so that the liquid level remains constant. The temperature of the boiling fluids was measured with a thermocouple. All the thermocouples used in the experiments were of $\mathrm{K}$ type.

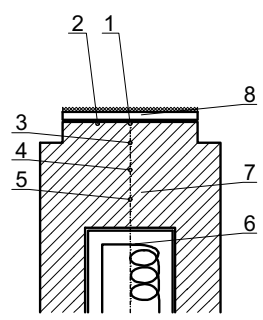

Figure 1. Schematic of the main unit of the experimental stand: 1,2 - thermocouples under the sample, $3,4,5$ thermocouples in the axis of the heating block, 6 - electric cartridge heater, 7 copper block, 8 - sample.

\section{Results and discussion}

The tests have been performed in the nucleate boiling mode under ambient pressure. The results have been presented in figures below - separately for each boiling liquid and the structural material of the coating. The results for the smooth surface (without any additional coating) have also been given for reference in order to conclude about the influence of the application of the microstructures. 
The impact of the height of the porous layer on boiling heat transfer of distilled water has been shown in Figure 2 for the copper meshes and in Figure 3 for the phosphor bronze meshes. While figures 4 and 5 present the results obtained for ethyl alcohol. The wire diameter of the copper meshes was $0,25 \mathrm{~mm}$ and $0,32 \mathrm{~mm}$ (which relates to the following height of the microstructures: $2 \times 0,25=0,50 \mathrm{~mm}$ and $2 \times 0,32=0,64 \mathrm{~mm}$ ), while of the bronze meshes: $0,20 \mathrm{~mm}$ and $0,25 \mathrm{~mm}$ (with structure height of $0,40 \mathrm{~mm}$ and $0,50 \mathrm{~mm}$, respectively). Consequently, an increase in the height of $28 \%$ for copper and $25 \%$ in the case of phosphor bronze meshes will be investigated.

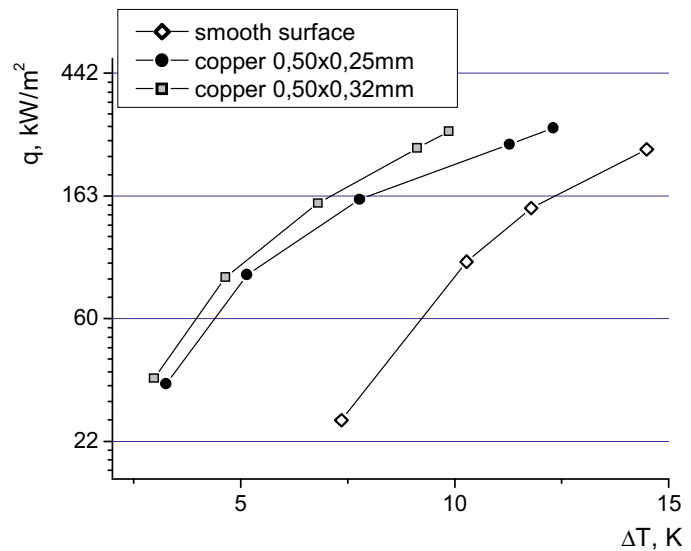

Figure 2. Distilled water test results - heat flux vs. wall superheat for copper meshes.

The results presented in Figure 2 indicate a significant enhancement of heat transfer with the application of mesh layers in comparison to the smooth reference surface. The heat flux dissipated from the higher structure proved to be larger than for the smaller mesh layer at the same superheats. As the superheat became higher the results for the microstructure coated surfaces approached the values obtained for the smooth surface without any coating. It is a typical feature reported in literature for boiling on porous coatings and might be related to the difficulties in vapour removal from the structure at higher temperature differences.

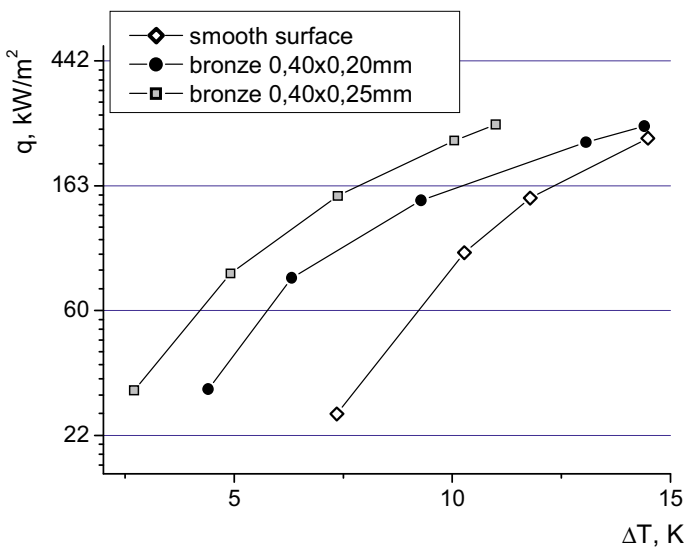

Figure 3. Distilled water test results - heat flux vs. wall superheat for phosphor bronze meshes.
The results for the bronze meshes (Fig. 3) confirm the findings reported earlier in Figure 2 that higher structures are more efficient in dissipating heat during boiling in the considered range of wall superheats. Here, the impact is even more significant than for the copper microstructure. The results for the mesh of the wire diameter of $0,20 \mathrm{~mm}$ considerably approach the values recorded for the smooth surface. A probable explanation is that the bronze layer is less efficient in heat removal during boiling due to lower thermal conductivity of the structure material. Besides rising rate of vapour generation makes it difficult for vapour to be removed in time from the mesh. As a consequence, the supply of fresh liquid from the surroundings is also hampered and the heat flux decreases.

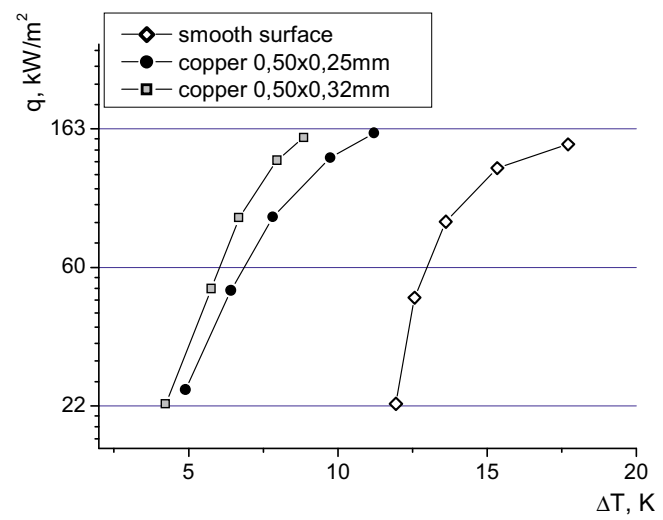

Figure 4. Ethyl alcohol test results - heat flux vs. wall superheat for copper meshes.

In the case of boiling of ethyl alcohol and copper mesh layers (Fig. 4), the higher structure also proved to be more efficient in the whole range of superheat values. The results for microstructure covered surfaces are much better in terms of dissipating heat than the smooth reference surface. It should be noted that the boiling curves for the microstructures are horizontally "shifted" to the left - to the region of small temperature differences. Consequently, the same heat flux can be dissipated at much smaller superheats (this reduction amounts to several Kelvin). It is a significant advantage, which enables more efficient heat transfer in phase change heat exchangers.

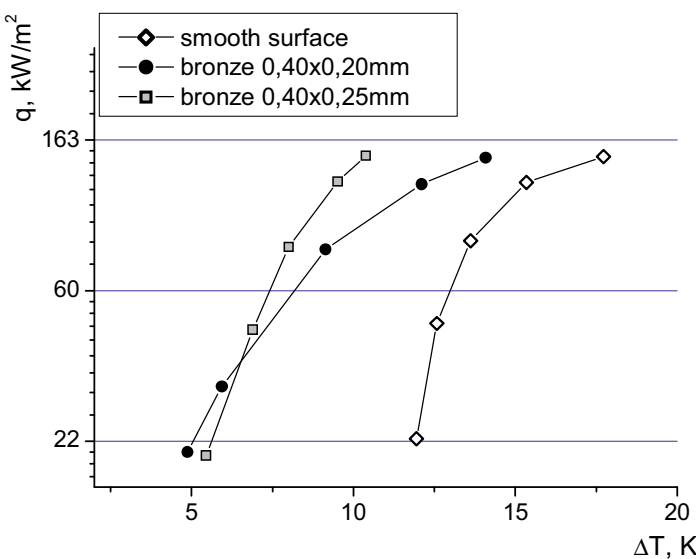

Figure 5. Ethyl alcohol test results - heat flux vs. wall superheat for phosphor bronze meshes. 
The analysis of Figure 5 indicates the same effect as in Fig. 3, namely a worse performance of the bronze layer of $0,20 \mathrm{~mm}$ wire diameter in the range of high wall superheats. For small superheat values - about $5 \mathrm{~K}$, the smaller structure seems more efficient. This phenomenon might be related to the fact that the thermal conductivity of bronze is relatively small comparing to copper and, thus, the temperature along the meshes is low. Consequently, boiling might be more affected by the nucleation site density rather than the temperature on the structure. This might explain a similar heat transfer performance in the region of low temperature differences and low heat fluxes.

It needs to be noted that, as the superheat increases, the inclination of all the boiling curves changes rapidly. They become more inclined and might even approach the values recorded for the smooth surface which was especially visible for the bronze mesh of the wire diameter 0,20 $\mathrm{mm}$. This phenomenon can be observed for both liquids but is more significant for distilled water. The generation of vapour is higher as the superheat rises. Consequently, it might be related to difficulties in vapour removal from the structure as superheat becomes much higher than in the isolated bubble regime of boiling and a lot of vapour is produced. In this case the mesh layer may even act as a barrier in vapour removal - especially in the case of water. Here, vapour bubbles are larger than for ethyl alcohol and their removal from the porous structure is more difficult. In the case of the smooth surface the active nucleation sites density increases with rising superheat (cracks and microcavities on the surface might be the sites where bubbles are produces and they become active with elevating temperature differences). At high superheats the heat flux could be similar for the smooth surface and the mesh coating, if the mesh hampers the efficient removal of vapour and the flow of fresh liquid to the microstructure.

\section{Conclusions}

Wire mesh coatings are currently widely used and researched, for example in heat pipes [14], which are highly efficient heat exchanging devices. It is the reason why the phase - change phenomena in such structures should be studied and experimentally analysed in detail.

The presented results indicate a significant enhancement of boiling heat transfer if mesh layers are applied on the heater. This improvement in relation to the smooth surface is most visible in the range of small superheats, which can also be observed for other microstructural coatings, for example metal - fibrous layers [15] and other kinds of meshes e.g. [16]. In the whole range of superheat values the heat flux for the mesh layer was higher in comparison to the smooth surface performance for both the working fluids.

It is worth noting that the application of the meshes on the heater surface makes it possible to dissipate the same heat flux at much smaller temperature differences. Thus, heat exchangers produced with microstructural coatings can be more efficient, which is vital for the industrial and power engineering applications.
It should also be observed that the meshes are an inexpensive method of boiling heat transfer enhancement. However, their application needs to be properly designed since some layers of incorrectly selected morphology and surface material might not be as effective in comparison to the smooth surface - especially in the region of high superheats - as presented in Fig 3.

Further experimental investigations of the impact of other microstructural parameters of the meshes are necessary in order to provide more data for the development of a reliable model of boiling heat transfer on structural coatings, which is still not available, and to enable a proper industrial design of efficient phase change heat exchangers.

\section{References}

1. S. Hasegawa, R. Echigo, S. Irie, J. of Nuclear Science and Technology, 12 [11], 722 - 724 (1975)

2. G.F. Smirnov, B.A. Afanasiev, Proc. VI Int. Heat Pipe Conf. "Advances in Heat Pipe Technology", $405-413$ (1982)

3. V.I. Tolubinskij, V.A. Antonenko, G.V. Ivanenko, Heat Transfer-Soviet Research, 21, 4, 531 - 535 (1989)

4. A.A. Vasil'yev, Heat Transfer Research, 24, 7, 913 921 (1992)

5. J.Y. Tsay, Y.Y. Yan, T.F. Lin, Heat and Mass Transfer, 32, 17 - 26 (1996)

6. J.W. Liu, D.J. Lee, A. Su, Int. J. of Heat and Mass Transfer, 44, 241 - 246 (2001)

7. A. Brausch, P.A. Kew, Proc. of 12 th Int. Heat Transfer Conf., 3 (2002)

8. D.W. Gerlach, Y.K. Joshi, Proc. of IMECE2005, IMCE2005-82595 (2005)

9. A. Franco, E.M. Latrofa, V.V. Yagov, Exp. Thermal and Fluid Science, 30, 263 - 275 (2006)

10. C. Li, G.P. Peterson, Journal of Heat Transfer, 128, 1320 - 1328 (2006)

11. S.-C. Wong, Y.-H. Kao, Int. Journal of Heat and Mass Transfer, 51, 4249 - 4259 (2008)

12. J.-H. Liou, C.-W. Chang, C. Chao, S.-C. Wong, Int Journal of Heat and Mass Transfer, 53, 1498 - 1506 (2010)

13. T. Orzechowski, A. Tyburczyk, Boiling heat transfer enhancement on a long fin coated with wire mesh structures, 8th Conf. on Experimental Heat Transfer, Fluid Mechanics, and Thermodynamics (2013)

14. P. Nemec, A. Čaja, M. Malcho, Testing thermal properties of the cooling device with heat pipes, EPJ Web of Conferences, 45, Proc. of 7th Int. Conf. on Experimental Fluid Mechanics 2012 (2013)

15. T.M. Wójcik, Experimental Investigations of Boiling Heat Transfer Hysteresis on Sintered, Metal Fibrous, Porous Structures, Exp. Thermal and Fluid Sc., 33, 397 - 404 (2009)

16. T. Orzechowski, Ł.J. Orman, Wymiana ciepła przy wrzeniu pęcherzykowym na żebrze z dwuwarstwową strukturą siatkową, XIII Symp. Wymiana Ciepła i Masy, 763 - 768 (2007) 